\title{
Oxygen toxicity, respiration and behavioural responses to oxygen in free-living anaerobic ciliates
}

\author{
TOM FENCHEL ${ }^{1 *}$ and BLAND J. FinLAY ${ }^{2}$ \\ ${ }^{1}$ Marine Biological Laboratory (University of Copenhagen), DK-3000 Helsingør, Denmark \\ ${ }^{2}$ Institute of Freshwater Ecology, Windermere Laboratory, Far Sawrey, Ambleside, Cumbria LA22 OLP, UK
}

(Received 10 April 1990; revised 13 June 1990; accepted 20 June 1990)

\begin{abstract}
Three species of marine, anaerobic free-living ciliates (Metopus contortus, Plagiopyla frontata and Parablepharisma collare) were studied with respect to their relation to $\mathrm{O}_{2}$. Survival was adversely affected at $\mathrm{O}_{2}$ tensions exceeding 1-2\% of atmospheric (air) saturation (atm. sat.): Parablepharisma collare survived for about $1 \mathrm{~h}$ at $100 \% \mathrm{~atm}$. sat., while the other two species survived the treatment for up to $2 \mathrm{~d}$. Survival in the presence of $\mathrm{O}_{2}$ depended on the composition of the medium; cells survived longer in clean seawater than in culture medium which, when exposed to $\mathrm{O}_{2}$, became toxic. This is probably related to peroxide production mediated by solutes in the culture medium: addition of catalase prolonged survival. The ciliates did not contain catalase. Two of the species harbour endosymbiotic methanogens; at $\mathrm{O}_{2}$ tensions exceeding $2 \% \mathrm{~atm}$. sat. the bacteria were inactivated, but they remained viable even after more than $5 \mathrm{~h}$ exposure to atmospheric $\mathrm{O}_{2}$ tension. Metopus contortus and Plagiopyla frontata respired $\mathrm{O}_{2}$ at rates similar to those of aerobic species; this $\mathrm{O}_{2}$ uptake is not coupled to energy conservation since the ciliates do not contain cytochromes, and low $\mathrm{O}_{2}$ tensions do not stimulate growth. $\mathrm{O}_{2}$ consumption is probably a detoxification mechanism which can maintain an intracellular anaerobic environment at a low ambient $\mathrm{O}_{2}$ tension. Metopus contortus and Plagiopyla frontata showed chemosensory behaviour in response to $\mathrm{O}_{2}$; this allowed them to find and remain within anaerobic microhabitats.
\end{abstract}

\section{Introduction}

Most anaerobic environments harbour unicellular eukaryotes with an $\mathrm{O}_{2}$-independent energy metabolism. Among these, the symbiotic forms living in the intestinal or urogenital tract of animals have so far attracted most attention (Müller, 1988, and references therein). Anaerobic protozoa also occur in aquatic sediments and in the water column of stratified lakes and anoxic marine basins, as well as in anaerobic sewage and in landfill sites (Fenchel, 1969; Fenchel et al., 1977, 1990; Finlay, 1980; van Bruggen et al., 1986; Wagener \& Pfennig, 1987; Goosen et al., 1988; Finlay et al., 1988). Among the freeliving forms, most is known about the anaerobic ciliates. All the species so far studied possess organelles which morphologically resemble mitochondria, but do not contain cytochromes. In some species these organelles contain a membrane-bound hydrogenase and are then referred to as hydrogenosomes. They are capable of oxidizing pyruvate completely to acetate, $\mathrm{CO}_{2}$ and $\mathrm{H}_{2}$ (Zwart et al., 1988; Finlay \& Fenchel, 1989). $\mathrm{H}_{2}$ excretion has previously been demonstrated in several urogenital, intestinal and rumen protozoa (Yarlett et al., 1984; Müller, 1988). Among the hydrogenosome-containing free-living ciliates, many also harbour endosymbiotic methanogenic bacteria which presumably depend on the $\mathrm{H}_{2}$ production of the host (van Bruggen et al., 1986; Wagener \& Pfenning, 1987; Goosen et al., 1988; Finlay \& Fenchel, 1989). The mechanism of energy metabolism of anaerobic ciliates which do not possess a hydrogenase is not known in any detail, but it must also be fermentative. Growth yields and growth rates are consistent with this assumption (authors' unpublished observations).

Among the parasitic anaerobic protozoa several forms (e.g. the trichomonad flagellates) are quite tolerant of $\mathrm{O}_{2}$, whereas the ciliates from the rumen tolerate only trace amounts of this gas (Lloyd et al., 1982; Müller, 1988). In all cases studied the organisms are capable of $\mathrm{O}_{2}$ respiration and the affinity for $\mathrm{O}_{2}$ is comparable to that of aerobic protozoa. The uptake of $\mathrm{O}_{2}$ by rumen ciliates is considered to be important for the maintenance of a low $\mathrm{O}_{2}$ tension in the rumen (Ellis et al., 1989). The terminal oxidase has not been identified with certainty in 
any case, but it is not cytochrome oxidase, and the $\mathrm{O}_{2}$ uptake is generally unaffected by respiratory inhibitors (Müller, 1988).

With regard to free-living forms, very little is known about their relationship to $\mathrm{O}_{2}$. In nature they occur only in reducing environments where $\mathrm{O}_{2}$ is undetectable. On the other hand, chemical gradients in sediments can be very steep, ranging from atmospheric $\mathrm{O}_{2}$ tension to complete anoxia over a few millimetres. In addition, chemoclines may move vertically or be destroyed rapidly due to changes in the intensity of oxygenic photosynthesis at the sediment surface or to increased water turbulence resulting in oxidation of the sediment to a considerable depth (Fenchel, 1969). Therefore in some sediments the anaerobes are likely to be periodically exposed to $\mathrm{O}_{2}$. It also seems likely that isolated anaerobic niches may become colonized by anaerobic protozoa via aerobic environments. In this paper we describe the responses to $\mathrm{O}_{2}$ in three species of free-living anaerobic ciliates.

\section{Methods}

Isolation and cultivation of the ciliates. Metopus contortus Kahl, Plagiopyla frontata $\mathrm{Kahl}$ and Parablepharisma collare $\mathrm{Kahl}$ were all isolated from anaerobic sediments collected in Nivå Bay about $15 \mathrm{~km}$ south of Helsingør, Denmark. They were grown in $125 \mathrm{ml} \mathrm{Hypo-Vials}$ capped with butyl stoppers and aluminium seals. The medium was $100 \mathrm{ml}$ seawater (salinity 32 parts per thousand) diluted with distilled water to a salinity of 18 parts per thousand, boiled with dried grass $\left(400 \mathrm{mg} \mathrm{1}^{-1}\right)$ and filtered. Two boiled wheat grains and a few drops of resazurin solution (as a redox indicator) were added finally. The medium was then bubbled with purified $\mathrm{N}_{2}$ gas (<5 p.p.m. $\mathrm{O}_{2}$ according to the supplier) and reduced with a few drops of a $10 \mathrm{~mm}$ sulphide solution prepared by dissolving $\mathrm{Na}_{2} \mathrm{~S}$ in deoxygenated water and neutralizing with $\mathrm{HCl}$. The vials were then capped and inoculated with $1 \mathrm{ml}$ containing 50-100 protozoan cells (together with a mixed community of bacteria to serve as food) through the butyl stoppers with a hypodermic syringe. During the growth phase of the protozoa, the $\mathrm{pH}$ remained at around 7 and the medium contained from 0.7 to $4 \mathrm{mM}$ sulphide after a few days of growth. At $20^{\circ} \mathrm{C}$ Metopus has a doubling time of about $60 \mathrm{~h}$ and the two other species have a doubling time of 20 $25 \mathrm{~h}$; the eventual yield was $100-200$ cells ml $^{-1}$. Plagiopyla and Metopus both have a hydrogenase and harbour methanogen symbionts. The mitochondria of Parablepharisma do not contain hydrogenase and the ciliate does not harbour methanogens; the cells are, however, densely covered by ectosymbiotic bacteria of unknown identity and function (Fenchel et al., 1977; T. Fenchel, unpublished observations).

Experimental methods. For experiments on the survival or behaviour of cells exposed to different $\mathrm{O}_{2}$ tensions, $50 \mu \mathrm{l}$ drops of cell suspensions were placed in the bottom of test tubes flushed with $\mathrm{N}_{2}$. The tubes were then closed with butyl stoppers and the desired amount of air injected into the tube with a hypodermic syringe. Surviving cells were counted directly with a dissection microscope and swimming behaviour recorded with a video camera (Sony DXC-101P) connected to a recorder (Panasonic AG-6100). When the recordings were viewed frame by frame (time interval $40 \mathrm{~ms}$ ) the position of individual cells was plotted on a transparent overlay on the monitor. Some survival experiments were also made using Hypo-Vials, with a $10 \mathrm{~mm}$ layer of ciliate suspension in the bottom and with different $\mathrm{O}_{2}$ tensions in the head space. During the experiment the vials were gently agitated on a rotating table to secure equilibrium between the gas and the liquid phase. For counting cells, samples were withdrawn with a hypodermic syringe. Behaviour in $\mathrm{O}_{2}$ gradients was studied using microslide tubes (Camlab, Cambridge, UK) with internal dimensions of $4 \times 0.4 \mathrm{~mm}$. The capillaries were filled with an anoxic ciliate suspension (in a $\mathrm{N}_{2}$ atmosphere) and placed in a stoppered test tube in which the oxygen content of the gas phase was controlled through hypodermic needles penetrating the stoppers.

$\mathrm{O}_{2}$ uptake was measured in a $0.5 \mathrm{ml}$ thermostatically controlled respiration chamber with a stirring magnet and an $\mathrm{O}_{2}$ electrode (Radiometer, Copenhagen). Suspensions of washed cells (3000-5000 cells $\mathrm{ml}^{-1}$ ) in sterile seawater with initial $\mathrm{O}_{2}$ tensions of $10-20 \% \mathrm{~atm}$. sat. were used and the reading of the $\mathrm{O}_{2}$ meter was monitored until all $\mathrm{O}_{2}$ was consumed (Fig. 5). All experimental results refer to a temperature of $20{ }^{\circ} \mathrm{C} . \mathrm{O}_{2}$ tension is throughout given as a percentage of atmospheric (air) saturation (\% atm. sat.). With the salinity and temperature of the experiment $100 \%$ atm. sat. corresponds to $0.26 \mathrm{mM}-\mathrm{O}_{2}$.

Endosymbiont methanogens were quantified microscopically using the autofluorescence of coenzyme $F_{420}$ characteristic of these bacteria (Zehnder, 1988). Ciliates were fixed in $2 \%(v / v)$ formaldehyde (final concentration) in seawater and concentrated on black Nuclepore filters. The filters were mounted with immersion oil under a coverslip and viewed using an epifluorescence microscope (Olympus) with violet excitation.

\section{Results}

\section{Effect of $\mathrm{O}_{2}$ on survival}

$\mathrm{O}_{2}$ adversely affected the survival of all three species (Figs 1-4), but the species differed in their sensitivities. Survival time for a given $\mathrm{O}_{2}$ tension also depended on the medium. Cells which were washed (by centrifugation) and placed in clean, filtered seawater survived longest; at atmospheric $\mathrm{O}_{2}$ tension some Plagiopyla and Metopus

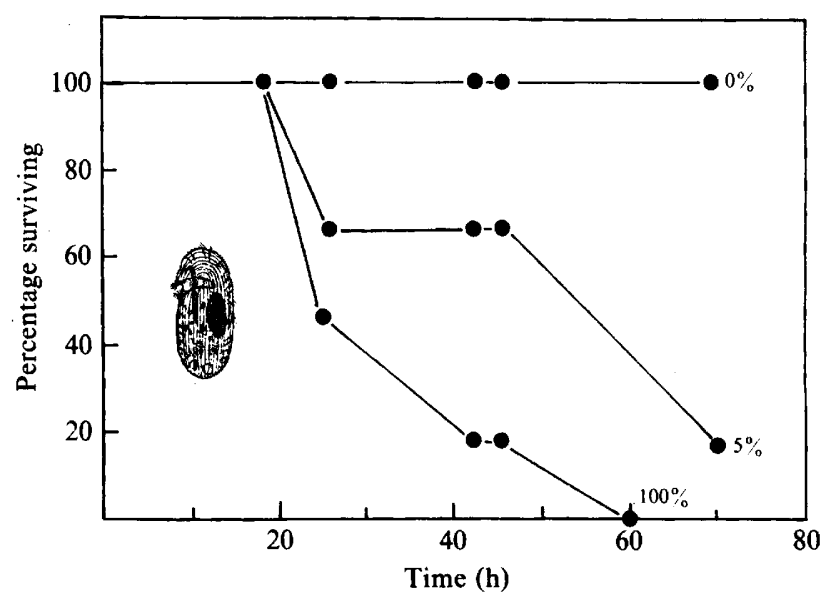

Fig. 1. Survival of Plagiopyla frontata in drops of sterile, clean seawater, the headspace being $\mathrm{N}_{2}$ plus different percentages of atmospheric air. There were initially about 20 cells for each treatment. 


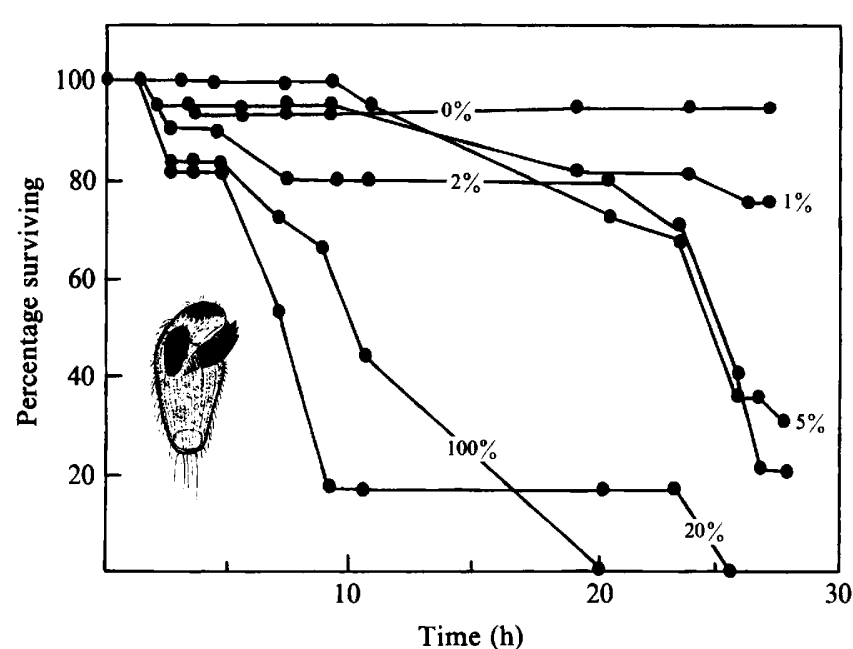

Fig. 2. Survival of Metopus contortus in drops of sterile, clean seawater, the headspace being $\mathrm{N}_{2}$ plus different percentages of atmospheric air. There were initially about 20 cells for each treatment.

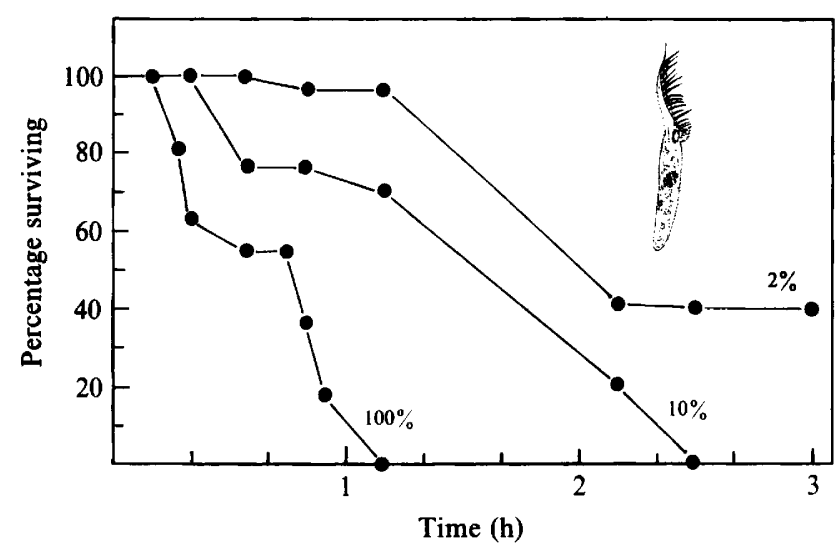

Fig. 3. Survival of Parablepharisma collare in Hypo-Vials containing about $10 \mathrm{ml}$ sterile clean seawater and initially about $100 \mathrm{cells} \mathrm{ml}^{-1}$, the headspace being $\mathrm{N}_{2}$ with different percentages of atmospheric air. Each sample was $0.5 \mathrm{ml}$. No vial with $0 \% \mathrm{O}_{2}$ was employed in this experiment.

cells survived for several days, whereas Parablepharisma cells lived for only about $1 \mathrm{~h}$. At lower $\mathrm{O}_{2}$ tensions survival increased in all species (Figs 1-3). It is possible that Metopus and Plagiopyla can survive very low $\mathrm{O}_{2}$ tensions indefinitely. They can be grown in open, unstirred hypovials, but anoxia at the bottom or within aggregates of bacteria is likely to occur. In one experiment, cultures of these two species were bubbled with $\mathrm{N}_{2}$ plus $2 \%$ atmospheric air. The cells survived for more than $200 \mathrm{~h}$, but they did not grow. In a control vial bubbled with pure $\mathrm{N}_{2}$ Metopus (but not Plagiopyla) did increase in numbers for several generations.

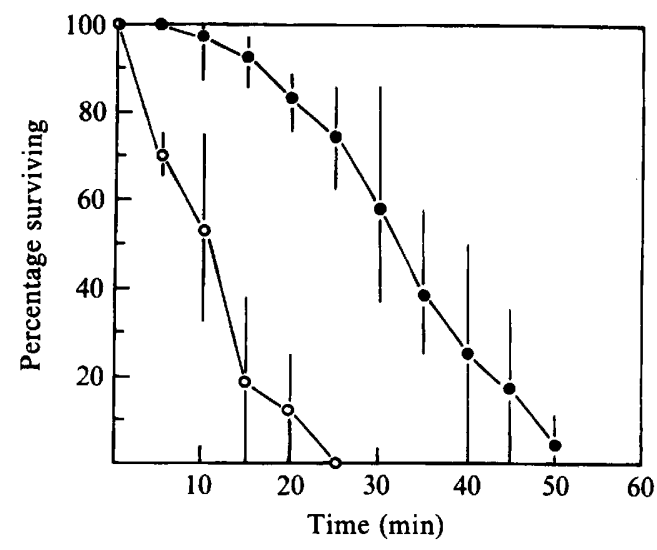

Fig. 4. Survival of Parablepharisma collare in drops of culture medium exposed to atmospheric air, with $(O)$ and without $(O)$ added catalase $(0 \cdot 1 \%)$. Three experiments were performed for each treatment and the mean and total range for each set of counts are shown. Each drop initially contained about 20 cells.

If the cells remained in the culture medium when exposed to $\mathrm{O}_{2}$, survival was much poorer: in one experiment maximum survival time for Metopus was $5.5 \mathrm{~h}$, and for Parablepharisma, less than $30 \mathrm{~min}$. The presence of $0.1 \%$ catalase (bovine liver, Sigma) restored survival time to that characteristic for clean seawater (Fig. 4). Catalase had no significant effect on survival in clean, oxygenated seawater. Part of the greater $\mathrm{O}_{2}$ toxicity of the medium was due to the presence of the redox dye resazurin; when this dye was added to clean seawater (final concentration 2 p.p.m.) survival time decreased in the presence of $\mathrm{O}_{2}$, but this effect was ameliorated by catalase. Adding sulphide to oxygenated water did not decrease survival. Addition of $0.1 \%$ superoxide dismutase (from bovine erythrocytes, Sigma) either had no effect or decreased survival in the presence of $\mathrm{O}_{2}$. Thus Metopus cells in culture medium with superoxide dismutase all died between 3 and $6 \mathrm{~h}$ when exposed to air while $75 \%$ of the cells were alive after $6 \mathrm{~h}$ in a control experiment without superoxide dismutase.

When 2-3 drops (corresponding to $80-120 \mu \mathrm{l}$ ) of a $3 \%$ (v/v) $\mathrm{H}_{2} \mathrm{O}_{2}$ solution was added to $1 \mathrm{ml}$ of a sufficiently dense suspension of aerobic ciliates, bubble formation was clearly evident. This effect was not observed with any of the three anaerobic ciliates studied, indicating the absence of catalase activity. Survival was $100 \%$ for an aerobic ciliate (Euplotes sp.) exposed to $5 \mu \mathrm{M}-\mathrm{H}_{2} \mathrm{O}_{2}$ and $40 \%$ after $6 \mathrm{~h}$ in $25 \mu \mathrm{M}-\mathrm{H}_{2} \mathrm{O}_{2}$. In contrast, both solutions killed $100 \%$ of Metopus cells within $40-60 \mathrm{~min}$.

When the ciliates had been exposed to $\mathrm{O}_{2}$ there was a time lag before they resumed cell division following reincubation in anaerobic culture medium. The duration of this lag depended on the duration of the exposure to $\mathrm{O}_{2}$ : 
Table 1. Quenching of methanogen fluorescence as function of $\mathrm{O}_{2}$ tension and exposure time

\begin{tabular}{|c|c|c|c|c|c|c|c|}
\hline \multirow[b]{2}{*}{ Organism } & \multirow{2}{*}{$\begin{array}{l}\text { Exposure } \\
\text { (h) }\end{array}$} & \multicolumn{6}{|c|}{$\begin{array}{c}\text { Fluorescence* at } \mathrm{O}_{2} \\
\text { tension (atm. sat.) shown: }\end{array}$} \\
\hline & & $0 \%$ & $1 \%$ & $2 \%$ & $5 \%$ & $10 \%$ & $20 \%$ \\
\hline \multirow{4}{*}{ Metopus } & 2 & + & + & + & + & + & + \\
\hline & 23 & + & + & + & - & - & - \\
\hline & 40 & + & + & + & - & - & - \\
\hline & 64 & + & + & + & - & - & - \\
\hline \multirow[t]{3}{*}{ Plagiopyla } & 2 & + & + & + & + & + & + \\
\hline & 22 & + & + & + & \pm & - & - \\
\hline & 51 & + & + & \pm & $\overline{-}$ & - & - \\
\hline
\end{tabular}

$*+$, Fluorescence normal; - , fluorescence absent; \pm , only a small fraction of the cells showed fluorescence.

thus Plagiopyla cells exposed to $100 \%$ atm. sat. for 5 or $10 \mathrm{~min}$ had a lag of 10-12 h, cells exposed for $20 \mathrm{~min}$ or $1 \mathrm{~h}$ had lag times of 20 and $22 \mathrm{~h}$, respectively, and cells exposed for $5 \mathrm{~h}$ did not resume exponential growth until after about $160 \mathrm{~h}$ in an anaerobic environment.

\section{Effects of $\mathrm{O}_{2}$ on methanogenic endosymbionts}

When Plagiopyla and Metopus cells were exposed to $\mathrm{O}_{2}$ for a sufficiently long time the autofluorescence of the endosymbiont methanogens disappeared (Table 1). This was due to the destruction of the $F_{420}$-hydrogenase enzyme complex (Zehnder, 1988) and it presumably reflects inactivation of methanogenesis. At an $\mathrm{O}_{2}$ tension of $1-2 \% \mathrm{~atm}$. sat., fluorescence was apparently sustained indefinitely. At $100 \%$ atm. sat., fluorescence was destroyed within $5 \mathrm{~min}$ in Metopus and after somewhat longer in Plagiopyla. In all cases fluorescence reappeared within a few hours if the ciliates were reincubated in an anaerobic medium. In Plagiopyla cells kept for $5 \mathrm{~h}$ at atmospheric $\mathrm{O}_{2}$ tension, the methanogens first regained fluorescence after $15-20 \mathrm{~h}$ in an anoxic environment. During subsequent cell divisions of the ciliate hosts the bacterial numbers per cell remained almost constant; therefore the viability of the methanogens was unaffected even after a relatively long exposure to atmospheric $\mathrm{O}_{2}$ tension.

\section{$\mathrm{O}_{2}$ uptake}

It was not possible to measure $\mathrm{O}_{2}$ uptake in Parablepharisma due to its poor survival under aerobic conditions. Metopus and Plagiopyla showed very similar uptake patterns. At $\mathrm{O}_{2}$ tensions exceeding about $5 \%$ atm. sat., uptake was saturated at $0 \cdot 1-0 \cdot 15 \mathrm{nl} \mathrm{O}_{2} \mathrm{~h}^{-1}$ per cell. The
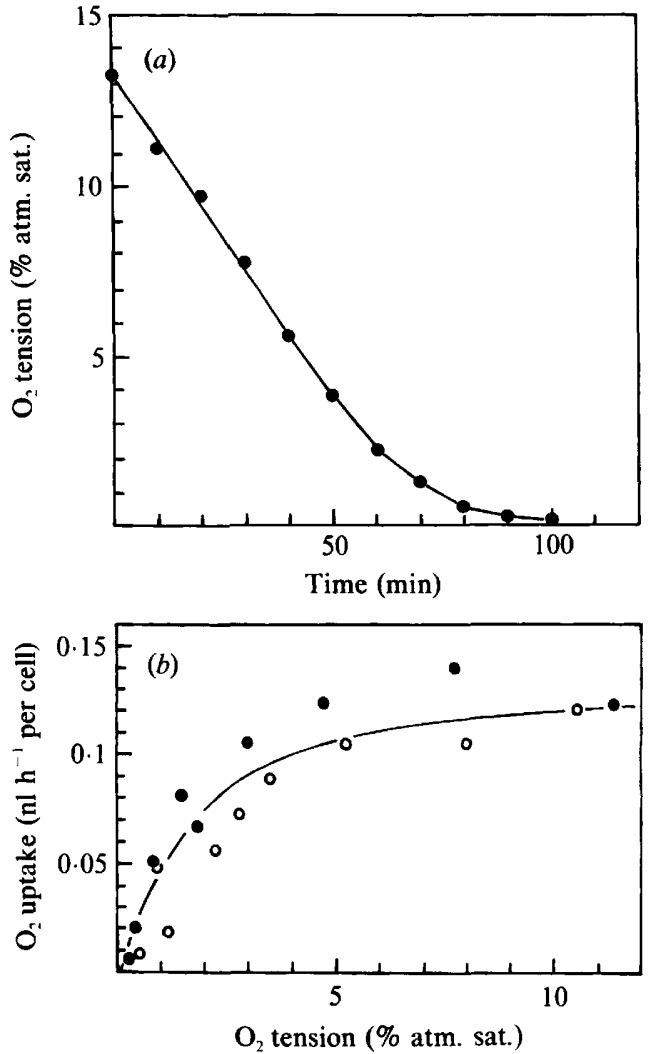

Fig. 5. (a) $\mathrm{O}_{2}$ tension as a function of time in a respiration chamber with Metopus cells ( 5000 cells $\mathrm{ml}^{-1}$ ). (b) $\mathrm{O}_{2}$ uptake of Metopus cells as a function of $\mathrm{O}_{2}$ tension; results from two experiments such as those shown above are given $(0, O)$.

apparent half-saturation constant was about or slightly more than $1 \%$ atm. sat. or, at the ambient temperature and salinity, about $2.6 \mu \mathrm{M}$ (Fig. 5).

\section{Chemosensory responses to $\mathrm{O}_{2}$}

The fact that the anaerobic ciliates showed chemosensory behaviour to $\mathrm{O}_{2}$ tension and they were capable of respiration was most easily illustrated by adding a sufficiently dense cell suspension of Metopus or Plagiopyla to oxic water. The ciliates rapidly clumped together in response to the layer of decreased $\mathrm{O}_{2}$ tension surrounding neighbouring cells (Fig. 6). One mechanism which partly explains this effect is a kinetic response, that is, that the motility of the cells is at a minimum under optimum conditions, so they tend to accumulate there. Fig. 7 shows the swimming velocity of Metopus cells exposed to different $\mathrm{O}_{2}$ tensions; it is seen that the cells responded by increasing their swimming velocity at $\mathrm{O}_{2}$ tensions exceeding $1 \%$ atm. sat. or less.

Cells also showed a phobic response in $\mathrm{O}_{2}$ gradients; that is, they reacted with ciliary reversals (tumbling) 


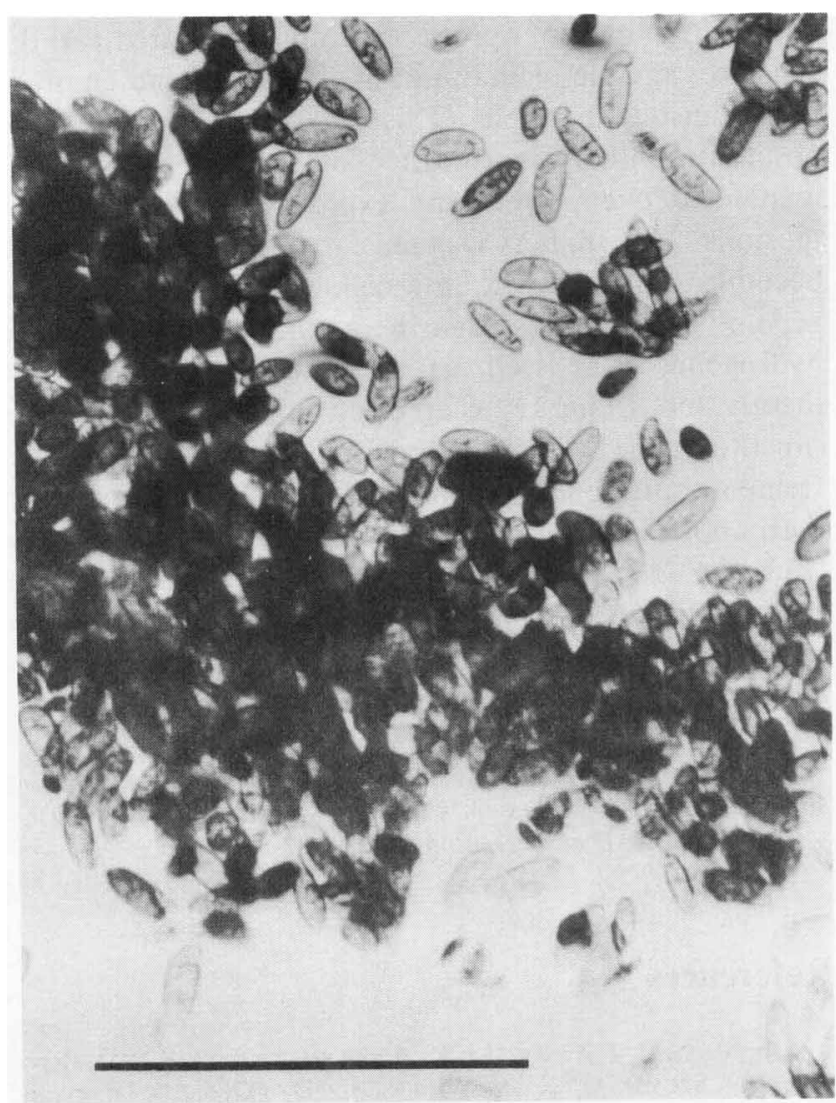

Fig. 6. Plagiopyla frontata cells clumping together after being immersed in oxygenated water. Bar, $0.5 \mathrm{~mm}$.

when swimming from an anoxic zone into one containing oxygen. This was easily observed in experiments such as that shown in Fig. 8. A microslide tube open at one end

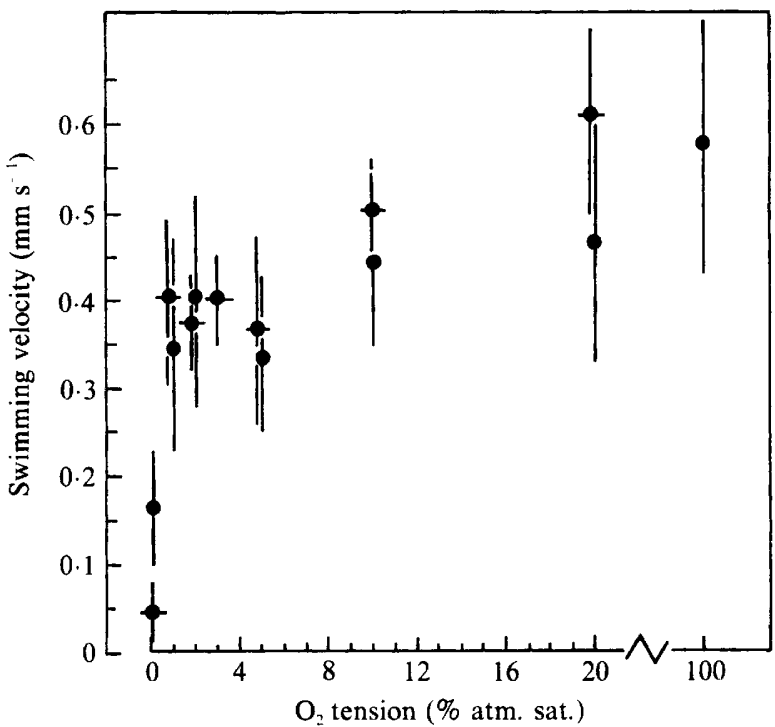

Fig. 7. Swimming velocity of Metopus contortus at different $\mathrm{O}_{2}$ tensions. Two experiments are shown. In one experiment $(O)$ the cells were returned to anoxia between each recording to allow them to recover the low swimming velocity characteristic of anoxia. In the other experiment (- $-\mathrm{O}_{2}$ tension was increased after each recording and $10 \mathrm{~min}$ of acclimatization was allowed after each change in $\mathrm{O}_{2}$ tension. Each data point represents the mean of ten swimming tracks and the standard deviation.

and filled with an anaerobic ciliate suspension was placed in a test tube in which the atmospheric composition could be controlled by hypodermic needles which penetrated the butyl stopper. At an $\mathrm{O}_{2}$ tension as low as $1 \%$ atm. sat. the Metopus cells retreated from the meniscus while the microaerophilic Euplotes sp. (see Fenchel et al., 1989) congregated there.

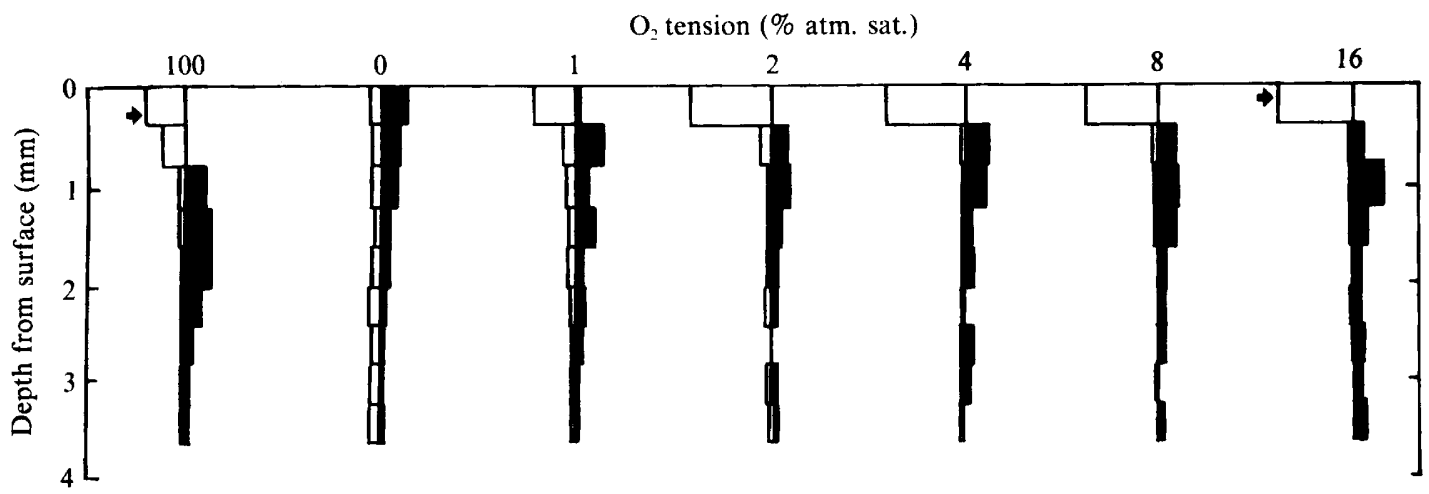

Fig. 8. Distribution of Metopus contortus $(\square)$ and the microaerophilic Euplotes sp. $(\square)$ in a microslide tube in atmospheres with different $\mathrm{O}_{2}$ tensions. Block size is proportional to cell numbers. Most of the contents of the capillary remained anoxic due to the respiration of the cells (about 100 of each species). At the highest external $\mathrm{O}_{2}$ tension the Euplotes also retreats from the meniscus since it prefers an $\mathrm{O}_{2}$ tension of $5 \% \mathrm{~atm}$. sat. (see Fenchel et al., 1989). Thus the arrow, which indicates the maximum density of Euplotes, also indicates an $\mathrm{O}_{2}$ tension of $5 \% \mathrm{~atm}$. sat. There was an interval of $15 \mathrm{~min}$ between recordings of the position of the cells after changing the atmospheric composition. 


\section{Discussion}

Our results suggest that anaerobic protozoa vary with respect to $\mathrm{O}_{2}$ sensitivity. We could not find evidence that any of the species we studied can grow at low $\mathrm{O}_{2}$ tensions. Survival experiments and observations of behaviour suggest that the organisms certainly have a preference for a $\mathrm{pO}_{2}<1 \%$ atm. sat. Goosen et al. (1988, 1990) found that the limnic Plagiopyla nasuta and Trimyema compressum could grow with $\mathrm{O}_{2}$ tensions in the gas phase up to about $5 \%$ atm. sat. In neither case, however, was there evidence to suggest that $\mathrm{O}_{2}$ uptake was coupled to energy conservation.

$\mathrm{O}_{2}$ toxicity is a complex phenomenon (e.g. Morris, 1979). One important element of toxicity is the oxygen radicals which are produced when reduced compounds are oxidized, either biologically or spontaneously, by $\mathrm{O}_{2}$. Our findings suggest that peroxide formation in oxygenated water, in conjunction with the absence of cellular catalase in anaerobic protozoa, is one reason for the toxic effect of $\mathrm{O}_{2}$ on these organisms. The observation that the presence of superoxide dismutase in the medium tends to augment rather than to decrease $\mathrm{O}_{2}$ toxicity suggests that the superoxide radical is the lesser peril compared to peroxide. It is apparent, however, that peroxide is not the only critical component of $\mathrm{O}_{2}$ toxicity since catalase has no life-prolonging effect in clean oxygenated seawater. The formation of peroxide and superoxide following oxygenation of anaerobic growth media has previously been demonstrated by Carlsson et al. (1978).

In Metopus and in Plagiopyla there are three obvious targets for $\mathrm{O}_{2}$ toxicity: the hydrogenase, the pyruvate:ferrodoxin oxidoreductase, and the endosymbiont methanogens, although the latter are not essential for the survival of the hosts (Wagener \& Pfennig, 1987; authors' unpublished results). It is therefore surprising that of the three ciliates studied, Parablepharisma, which has neither a hydrogenase nor methanogen symbionts (T. Fenchel, unpublished results), is by far the most $\mathrm{O}_{2}$ sensitive. We have no explanation for this. Some unusual features of the biochemistry of Parablepharisma may be responsible. Alternatively, this ciliate may lack most of the molecular mechanisms offering defence against $\mathrm{O}_{2}$ toxicity (e.g. Frank \& Massaro, 1980). It is unlikely to be completely devoid of defence mechanisms since it will, like all ciliates in anaerobic and low- $\mathrm{O}_{2}$ environments (Finlay et al., 1986), be periodically exposed to elevated levels of $\mathrm{O}_{2}$.

Chemosensory responses to $\mathrm{O}_{2}$ allow the ciliates to orient themselves in $\mathrm{O}_{2}$ gradients and to seek out anaerobic micropatches, providing some defence against $\mathrm{O}_{2}$ toxicity. Another aspect of their defence against $\mathrm{O}_{2}$ toxicity is their respiration. At low $\mathrm{O}_{2}$ tensions $(<1-2 \%$ atm. sat.), where uptake is almost linearly proportional to
$\mathrm{O}_{2}$ tension, uptake is probably diffusion-limited and the cells are capable of maintaining an anaerobic environment inside the cell. This is consistent with the observation that fluorescence of the methanogens is unaffected even after long exposure to such low $\mathrm{O}_{2}$ tensions. At higher $\mathrm{O}_{2}$ tensions, when $\mathrm{O}_{2}$ uptake becomes saturated, the intracellular environment must become oxic. It must then be assumed that the ciliate hydrogenases as well as the methanogens become inactivated. Using $\mathrm{O}_{2}$ as an electron sink may then be a substitute for $\mathrm{H}_{2}$ production in the maintenance of a fermentation redox balance (cf. Müller, 1988). Most methanogens are extremely sensitive to oxygen (Zehnder, 1988). It is therefore noteworthy that the endosymbiotic methanogens remain viable and are capable of growth when returned to anoxic conditions even after prolonged exposure to $\mathrm{O}_{2}$.

We acknowledge the technical assistance of Ms Jeanne Johansen and Ms Alexandra $C$. Nielsen. The study was supported by grant no. 11-8391 from the Danish Natural Science Research Council.

\section{References}

van Bruggen, J. J. A., Zwart, K. B., Hermans, J. G. F., van Hove, E. M., Stumm, C. K. \& Vogels, C. D. (1986). Isolation and characterization of Methanoplanus endosymbiosus sp. nov., an endosymbiont of the marine sapropelic ciliate Metopus contortus. Archives of Microbiology 144, 367-374.

CARLSSON, J., NYBERG, G. \& WRETHÉN, J. (1978). Hydrogen peroxide and superoxide radical formation in anaerobic broth media exposed to atmospheric oxygen. Applied and Environmental Microbiology 36, 223-229.

Ellis, J. E., Williams, A. G. \& Lloyd, D. (1989). Oxygen consumption by ruminal microorganisms: protozoal and bacterial contributions. Applied and Environmental Microbiology 55, 25832587.

FENCHEL, T. (1969). The ecology of marine microbenthos. IV. Structure and function of the benthic ecosystem, its chemical and physical factors and the microfauna communities with special reference to the ciliated protozoa. Ophelia 6, 1-182.

Fenchel, T., Perry, T. \& Thane, A. (1977). Anaerobiosis and symbiosis with bacteria in free-living ciliates. Journal of Protozoology 24, 154-163.

Fenchel, T., Finlay, B. J. \& GianNI, A. (1989). Microaerophily in ciliates: responses of an Euplotes species (Hypotrichida) to oxygen tension. Archiv für Protistenkunde 137, 317-330.

Fenchel, T., KRISTENSEN, L. D. \& RAsmussen, L. (1990). Water column anoxia: vertical zonation of planktonic protozoa. Marine Ecology Progress Series 62, 1-10.

FINLAY, B. J. (1980). Temporal and vertical distribution of ciliophoran communities in the benthos of a small eutrophic loch with particular reference to the redox profile. Freshwater Biology 10, 15-34.

FInLAY, B. J. \& FencheL, T. (1989). Hydrogenosomes in some anaerobic protozoa resemble mitochondria. FEMS Microbiology Letters 65, 311-314.

Finlay, B. J., FenChel, T. \& Gardener, S. (1986). Oxygen perception and $\mathrm{O}_{2}$ toxicity in the freshwater ciliated protozoon Loxodes. Journal of Protozoology 33, 157-165.

Finlay, B. J., Clarke, K. J., Cowling, A. J., Hindle, R. M., Rogerson, A. \& BERNINGER, U.-G. (1988). On the abundance and distribution of protozoa and their food in a productive freshwater pond. European Journal of Protistology 23, 205-217. 
Frank, L. \& MASSARo, D. (1980). Oxygen toxicity. American Journal of Medicine 69, 117-126.

Goosen, N. K., Horemans, A. M. C., Hillebrand, S. J. W., Stumm, C. K. \& VogeLs, G. D. (1988). Cultivation of the sapropelic ciliate Plagiopyla nasuta Stein and isolation of the endosymbiont Methanobacterium formicicum. Archives of Microbiology 150, 165-170.

Goosen, N. K., WAGENER, S. \& STUMM, C. K. (1990). A comparison of two strains of the anaerobic ciliate Trimyema compressum. Archives of Microbiology 53, 187-192.

Lloyd, D., Williams, J., Yarlett, N. \& Williams, A. G. (1982). Oxygen affinities of the hydrogenosome containing protozoa Tritrichomonas foetus and Dasytricha ruminantium, and two aerobic protozoa, determined by bacterial bioluminescence. Journal of General Microbiology 128, 1019-1022.

MORRIS, J. G. (1979). Nature of oxygen toxicity in anaerobic microorganisms. In Strategies of Microbial Life in Extreme Environments, pp. 149-162. Edited by M. Shilo. Berlin: Dahlem Konferenzen.
MÜLLER, M. (1988). Energy metabolism of protozoa without mitochondria. Annual Review of Microbiology 42, 165-188.

Wagener, S. \& Pfennig, N. (1987). Monoxenic culture of the anaerobic ciliate Trimyema compressum Lackey. Archives of Microbiology 149, 4-11.

Yarlett, N., Coleman, G. S., Williams, A. G. \& Lloyd, D. (1984) Hydrogenosomes in known species of rumen entodiniomorphid protozoa. FEMS Microbiology Letters 21, 15-19.

ZEHNDER, A. J. B. (1988). Biology of Anaerobic Microorganisms. New York: John Wiley \& Sons.

Zwart, K. B., Goosen, N. K., van SchiJndel, M. W., Broers, C. A. M., Stumm, C. K. \& Vogels, G. D. (1988). Cytochemical localization of hydrogenase activity in the anaerobic protozoa Trichomonas vaginalis, Plagiopyla nasuta and Trimyema compressum. Journal of General Microbiology 134, 2165-2170. 